\title{
In Vitro Studies of Poison Oak Immunity
}

\section{IN VITRO REACTION OF HUMAN LYMPHOCYTES TO URUSHIOL}

\author{
Vera S. Byers, William L. Epstein, Neal Castagnoli, and H. Baer, Department \\ of Dermatology and Department of Pharmaceutical Chemistry, University of \\ California, San Francisco, San Francisco, California 94143; and Bureau of \\ Biologics, Food and Drug Administration, Bethesda, Maryland 20014
}

\begin{abstract}
A B S T R A C T Poison oak, ivy, and sumac dermatitis is a T-cell-mediated reaction against urushiol, the oil found in the leaf of the plants. This hapten is extremely lipophilic and concentrates in cell membranes. A blastogenesis assay employing peripheral blood lymphocytes obtained from humans sensitized to urushiol is described. The reactivity appears $1-3$ wk after exposure and persists from $6 \mathrm{wk}$ to $2 \mathrm{mo}$. The doseresponse range is narrow, with inhibition occurring at higher antigen concentrations. Urushiol introduced into the in vitro culture on autologous lymphocytes, erythrocytes and heterologous erythrocytes produces equal results as measured by the optimal urushiol dose, the intensity of reaction, and the frequency of positive reactors. This suggests that the urushiol is passed from introducer to some other presenter cell. Although the blastogenically reactive cell is a $\mathrm{T}$ cell, there is also a requirement for an accessory cell, found in the nonT-cell population, for reactivity. Evidence is presented that this cell is a macrophage.
\end{abstract}

\section{INTRODUCTION}

Poison oak, poison ivy, and poison sumac plants are members of the family Anacardiaceae. These plants produce an oil which can cause contact sensitivity in humans and animals. The dermatitis is minimal upon the initial sensitizing exposure, but subsequent exposures result in erythematous-indurated suppurating lesions at the site of application appearing 24-48 h later (1). Approximately $80 \%$ of the United States population is immune to poison oak or ivy because of prior exposure, and $50 \%$ are clinically reactive $(2)$. The debilitating dermatitis resulting from contact with the

Received for publication 7 February 1979 and in revised form 11 June 1979. plant represents a severe hazard for outdoor workers $(3,4)$. For this reason there is a great interest in developing a method of tolerizing such "at risk" individuals against poison oak, ivy, and sumac.

The oils extracted from all three plants are closely related chemically and are called urushiols. They are composed of mixtures of 3- $n$-alk(en)ylcatechols (Fig. 1) in which the side chains consist of either a C-15 or a C-17 moiety. The saturated and the mono-, di-, and triene forms are present. Whereas urushiol derived from poison ivy is composed predominantly of compounds with C-15 side chains (5), poison oak urushiol contains more of the compounds with $\mathrm{C}-17$ side chains $(6,7)$. The di- and tri-olefins are the major components of both urushiols, and the two oils are highly cross reactive (8). In vivo studies in humans sensitized by accidental exposure have shown that the dienes and the trienes are far more antigenic than the saturated components of the urushiol mixture, 3-n-pentadecycatechol (PDC) ${ }^{1}$ and 3-n-heptadecylcatechol (HDC), which are about one-tenth as active as the corresponding dienes (9).

An in vitro blastogenesis assay for cellular immunity to poison oak using human peripheral blood lymphocytes was developed to define the nature of the reaction, the specificity of the antigen receptors, and, eventually, to test analogues for their tolerogenic potential.

\footnotetext{
${ }^{1}$ Abbreviations used in this paper: Con A, concanavalin A; DMSO, dimethyl sulfoxide; HBSS, Hanks' balanced salt solution; HDC, 3-n-hepatadecylcatechol; Ly-control, control lymphocytes; Ly-uru, lymphocytes with $100 \mu \mathrm{g}$ of catechol; ME, membrane equivalent(s); PDC, 3-n-pentadecylcatechol; PHA, phytohemagglutinin; PWM, pokeweed mitogen; RBC, erythrocyte(s); RBC-control, RBC with neither urushiol nor PDC; RBC-PDC, RBC with PDC; RBC-uru, RBC with urushiol; RP, rosette poor; RPMI-auto, RPMI-1640 with $20 \%$ autologous serum; RR, rosette rich; TP, total population(s).
} 


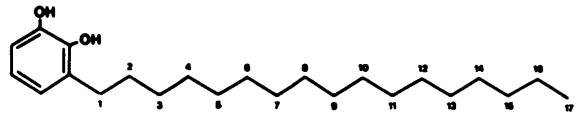

3-n-Meptadocylembehol (HOC)
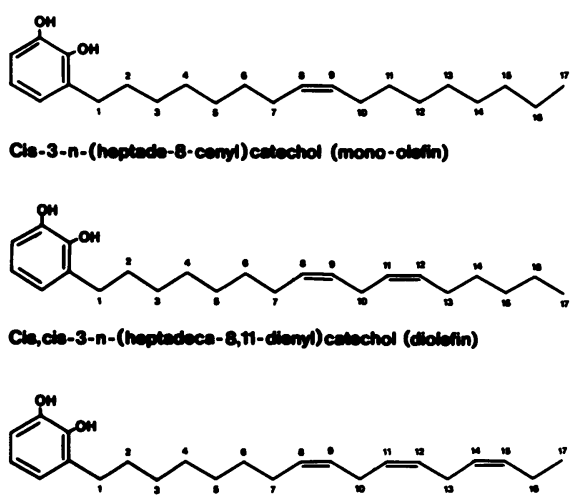

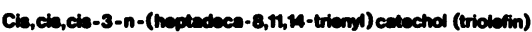

FIGURE 1 Structures of alkylcatechols found in poison oak urushiol. The C-17 compounds are shown; C-15 compounds are also found.

\section{METHODS}

\section{Microassay for blastogenesis}

\section{ANTIGEN PREPARATION}

Human peripheral blood was defibrinated on glass beads and centrifuged at $200 \mathrm{~g}$ for $30 \mathrm{~min}$ at room temperature. Packed erythrocytes (RBC) were removed for antigen preparation. The RBC were washed three times with $40 \mathrm{ml}$ of Hanks' balanced salt solution (HBSS, Grand Island Biological Co., Grand Island, N. Y.), the buffy coat being discarded after each centrifugation. At the end of the procedure no leukocytes were visible in $0.2 \mathrm{ml}$ of a waterlysed pellet. Urushiol is not water soluble. Therefore, all membrane antigen preparations were prepared in $10 \%$ dimethyl sulfoxide (DMSO) in HBSS. RBC ( $10^{10}$ cells) were resuspended in 4.5-ml aliquots of HBSS to which was added $0.5 \mathrm{ml}$ of DMSO containing either urushiol (RBC-uru), or PDC (RBC-PDC), or neither (RBC-control). The amount of urushiol or PDC added ranged from 0.016 to $5.0 \mathrm{mg}$. After incubating for $30 \mathrm{~min}$ at room temperature, the cells were washed three times with $30 \mathrm{ml}$ of sterile, distilled water and centrifuged at $20,000 \mathrm{~g}$ for $30 \mathrm{~min}$ at $4^{\circ} \mathrm{C}$ producing a colorless membrane pellet. Microscopically, these appeared as RBC ghosts similar to that described elsewhere (10). Some membrane preparations called "DMSO washed" (described later) were subjected to three additional washes with $95 \%$ DMSO followed by a single sterile water wash. This material macroscopically appeared as a fine sand, and microscopically as individual grains $\cong 5-10$ microns in diameter. All membrane preparations were suspended at the appropriate concentrations in RPMI 1640 (Grand Island Biological Co.). They were freshly prepared each day because the antigenic activity of the suspension dropped after storage for 1 wk at $4^{\circ} \mathrm{C}$.

Sheep RBC antigen was prepared as above. Sheep RBC in Alsevers' solution were obtained from Microbiological Associates, Walkersville, Md.

Lymphocyte antigen was prepared by defibrinating peripheral blood and separating the lymphocytes on a Ficoll (Phar- macia Fine Chemicals, Inc., Piscataway, N. J.) -Hypaque (Winthrop Laboratories, New York) gradient. Lymphocytes $\left(10^{7}-10^{8}\right.$ cells) were resuspended in $9 \mathrm{ml}$ RPMI 1640 to which $1 \mathrm{ml}$ DMSO containing either $100 \mu \mathrm{g}$ catechol (Ly-uru) or no catechol (Ly-control) had been added. The suspension was incubated $30 \mathrm{~min}$ at $4^{\circ} \mathrm{C}$ and then washed twice in RPMI 1640 by centrifugation at $200 \mathrm{~g}$ and $4^{\circ} \mathrm{C}$. The resultant antigen was an intact, viable lymphocyte that excluded trypan blue and could take up and retain a ${ }^{51} \mathrm{Cr}$ label. The amount of antigen added to each culture can either be expressed as membrane equivalents (ME) or micrograms urushiol per culture.

\section{PREPARATION OF RESPONDER LYMPHOCYTES}

Total population. Peripheral blood was defibrinated, and lymphocytes were separated on Ficoll-Hypaque gradients. After washing twice in HBSS the lymphocytes were resuspended at the appropriate concentration in RPMI 1640 that contained $100 \mu \mathrm{g} / \mathrm{ml}$ streptomycin and 100 penicillin units $/ \mathrm{ml}$ (Grand Island Biological Co.) and 20\% autologous serum (RPMI-auto).

Rosette-rich and rosette-poor populations. Peripheral blood was drawn into a lipohepin (Riker Laboratories, Inc., Northridge, Calif.) -containing syringe, $50 \mathrm{U} / \mathrm{ml}$ final concentration, and the lymphocytes were separated on a FicollHypaque gradient. Rosette-rich lymphocyte populations were prepared as described by Littman (11), with the exception that sheep RBC (Microbiological Media, Concord, Calif.) -absorbed fetal calf serum (Grand Island Biological Co.) was used in place of human AB positive serum. Additionally, the sheep RBC were lysed by a 5-s treatment with water rather than with ammonium chloride solution. The population remaining after the rosette-rich population was removed was designated rosette poor. The rosette-rich population constituted $\cong 60 \%$ of the total lymphocyte population and was composed primarily of small lymphocytes (6-8 microns in diameter) with a few polymorphonuclear leukocytes. No platelets, monocytes, or cellular debris could be detected. The populations were reacted with fluorescein-labeled goat anti-human immunoglobulin (Ig)G obtained unconjugated from Antibodies, Inc., Davis, Calif., conjugated by Dr. J. Riggs (California State Department of Health, Berkeley, Calif.), and used for staining lymphocytes as previously described (12). No cellular staining was detected. The rosette-poor population made up the remaining $40 \%$ of the total population and consisted of rosette-negative lymphocytes, monocytes, and polymorphonuclear leukocytes. Virtually all these cells stained to some degree with fluorescein-labeled goat antihuman IgG.

Separation of adherent from nonadherent cells. Adherent cells were prepared by a slight modification of a previously described method (13). Peripheral blood lymphocytes were prepared as before, adjusted to $2 \times 10^{6}$ cells $/ \mathrm{ml}$ in RPMIauto, and $20 \mathrm{ml}$ was added to a sterile glass Erlenmeyer flask, $80-\mathrm{mm}$ diameter bottom, and incubated $1 \mathrm{~h}$ at $37^{\circ} \mathrm{C}$ in $5 \%$ $\mathrm{CO}_{2}-95 \%$ air. The nonadherent cells were then decanted into a second flask which was again incubated under the same conditions, decanted, and resuspended in RPMI-auto at the appropriate concentrations. The adherent cells in the first flask were washed with $20 \mathrm{ml}$ of warm RPMI-auto, then incubated $30 \mathrm{~min}$ at $37^{\circ} \mathrm{C}$ in $5 \% \mathrm{CO}_{2}$ with $20 \mathrm{ml}$ of RPMI-auto. The media was decanted, the flask washed twice with $10 \mathrm{ml}$ of HBSS, $20 \mathrm{ml}$ of phosphate-buffered saline was added, and the flask was refrigerated for $45 \mathrm{~min}$, after which the cells were scraped off with a sterile rubber policeman. These cells were 85-90\% viable. This yielded adherent cells representing $\cong 1 \%$ of the total population.

The esterase stains on cells in the depleted and glass- 
adherent cells were kindly performed by Professor J. Stobo (University of California, San Francisco) using previously described methods (14-16), and were used to estimate the percentage of macrophages in the cultures. Duplicate slides were prepared and counted.

\section{ASSAY}

Between $5 \times 10^{4}$ and $8 \times 10^{5}$ responder lymphocytes were added to each well of a microplate (Flow Laboratories, Inc., Rockville, Md.), in $0.1 \mathrm{ml}$ of RPMI-auto. RBC membrane antigen $(0.1 \mathrm{ml})$, or lymphocyte antigen $(0.1 \mathrm{ml})$ was added in various amounts to each well. The plates were incubated at $37^{\circ} \mathrm{C}$ in $5 \% \mathrm{CO}_{2}-95 \%$ air for $1-13 \mathrm{~d}$ and on the appropriate day $0.05 \mathrm{ml}\left[{ }^{14} \mathrm{C}\right]$ thymidine (Amersham Corp., Arlington Heights, Ill.) in RPMI 1640 with $10 \%$ fetal calf serum was added at a concentration of $0.5 \mu \mathrm{Ci} /$ well. About $24 \mathrm{~h}$ later the plates were harvested with a Titer Tec Harvester (Flow Laboratories, Inc.) and counted in a Beckman liquid scintillation counter (Beckman Instruments Inc., Fullerton, Calif.). The blastogenic index was calculated by dividing the counts per minute incorporated in cultures that contained RBC-uru or Ly-uru by the counts per minute incorporated in cultures containing RBC-control or Ly-control. Toxicity of the RBCuru antigen was tested by adding $0.375 \mu \mathrm{g} /$ well of phytohemagglutin (PHA, Pharmacia Fine Chemicals, Inc.), $6.25 \mu \mathrm{g} /$ well concanavalin A (Con A, ICN Life Sciences Group, Irvine, Calif.), or $3.1 \mu \mathrm{g} /$ well pokeweed mitogen (PWM, Grand Island Biological Co.) all in 0.05-ml aliquots. These doses of mitogens also were used to test the mitogenic capability of lymphocytes treated with urushiol directly.

\section{Preparation of alkylcatechols}

The synthesis of tritium-labeled HDC $(18 \mathrm{mCi} / \mathrm{mmol})$ was achieved by the following reaction sequence: A Grignard reaction between 2,3-dimethoxybenzaldehyde and $n$-hexadecyl bromide provided the carbinol which could be dehydrated to 1-(2,3-dimethoxyphenyl)-1-heptadecene. The olefin was treated with diborane and the intermediate trialkyboran was decomposed in ${ }^{3} \mathrm{H}_{2} \mathrm{O}$ to yield $\left[1-{ }^{3} \mathrm{H}\right](2,3$ dimethyoxyphenyl)$n$-heptadecane-1. Cleavage of the $O$-methyl ethers was achieved with boron tribromide. The reactions will be described in detail elsewhere. ${ }^{2}$

Urushiol oil was either extracted from poison ivy or poison oak, and prepared as previously described (6). The material used in this study was designated in that report (6) as the Mississippi lot. It is identified as either poison ivy or poison oak urushiol in that report (6), and was confirmed by mass spectral analysis to consist primarily of the di- and triolefins of C-15 or C-17 side-chain compounds. Both poison oak and poison ivy urushiols contain C-15 and C-17 compounds, but the C-15 compounds make up $>95 \%$ of poison ivy urushiol, and the C-17 compounds make up $>98 \%$ of poison oak urushiols. Unless otherwise stated, poison oak urushiols were used throughout our studies. It was supplied as the oil or diluted in acetone at $100 \mathrm{mg} / \mathrm{ml}$ in $1.0-\mathrm{ml}$ aliquots. It was dissolved in DMSO immediately before use and allowed to stand for $30 \mathrm{~min}$ at room temperature. $\left[{ }^{3} \mathrm{H}\right] \mathrm{Hydro}-$ urushiol ( $\cong 3 \mathrm{Ci} / \mathrm{mM}$ before dilution with $\mathrm{PDC}$ ) was prepared by hydrogenation of the urushiol mixture with tritiated gas.

Crystalline PDC was kindly provided by Dr. William Acres of Letterman General Hospital, San Francisco, Calif. It was

${ }^{2}$ Liberato, D., P. Jacob, and N. Castagnoli, Jr. Manuscript in preparation. stored at $-70^{\circ} \mathrm{C}$ under nitrogen gas until use. Crystalline HDC was prepared according to the route described for $\left[{ }^{3} \mathrm{H}\right] \mathrm{HDC}$.

\section{Catechol binding to membranes}

Solutions of $\left[{ }^{3} \mathrm{H}\right] \mathrm{PDC}$ and $\left[{ }^{3} \mathrm{H}\right] \mathrm{HDC}$ of varying specific activity were used to prepare antigen from RBC or lymphocytes as described above. They were then treated in one of the following ways: (a) RBC membranes were washed three times with $30 \mathrm{ml}$ of $95 \%$ DMSO and centrifuged at $20,000 \mathrm{~g}$ for $30 \mathrm{~min}$. At each wash the supernatant fluid was counted, and after the final wash the membranes were solubilized in $0.5 \mathrm{ml}$ of NCS solubilizer (Amersham Corp.) and counted. (b) The membranes were precipitated in $20 \mathrm{ml}$ of $1 \mathrm{~N} \mathrm{HClO}_{4}$ The precipitate was centrifuged, and the pellet was resuspended in $0.5 \mathrm{~N} \mathrm{TCA}$ in $95 \%$ ethanol. The precipitate was homogenized for 1 min using an Eberbach homogenizer (Eberbach Corp., Ann Arbor, Mich.), and the material was centrifuged $15 \mathrm{~min}$ at $200 \mathrm{~g}$. The supernatant fluid was decanted and counted. This washing procedure was repeated 3-5 times until the radioactivity in the supernatant fluid was at background level. The precipitates were washed once with water, neutralized with $1 \mathrm{~N} \mathrm{NaOH}$, solubilized with NCS solubilizer, and counted.

\section{Association of $\left[{ }^{3} \mathrm{H}\right]$ hydrourushiol with lymphocytes}

To determine if alkylcatechols presented on RBC become associated with lymphocytes during in vitro culture, $0.5 \mathrm{ml}$ of RBC-PDC was prepared as usual except that $\left[{ }^{3} \mathrm{H}\right]$ hydrourushiol, (1.6 $\times 10^{9} \mathrm{dpm} / \mathrm{mg}$ sp act) was used instead of PDC. A mixture of $2 \times 10^{7}\left[{ }^{3} \mathrm{H}\right] \mathrm{RBC}$-hydrourushiol ME and $2 \times 10^{6}$ lymphocytes in a total of $2 \mathrm{ml}$ of RPMI-auto in Corning $16 \times 125-\mathrm{mm}$ sterile test tubes (Corning Glass Works, Scientific Products Div., Corning, N. Y.) was prepared and incubated from 0 to $120 \mathrm{~h}$ at $37^{\circ} \mathrm{C}$ in $5 \% \mathrm{CO}_{2}-95 \%$ air. $\mathrm{A}$ separate tube that contained $0.5 \mathrm{ml}$ of $6\left[{ }^{3} \mathrm{H}\right] \mathrm{RBC}$-hydrourushiol was included as the control for the washing procedure. At various times triplicate tubes were removed and washed twice by centrifugation for $10 \mathrm{~min}$ at $200 \mathrm{~g}$ with $10 \mathrm{ml}$ HBSS, followed by a third wash with $10 \mathrm{ml}$ of phosphate buffered saline, $\mathrm{pH}$ 7.4. The pellet was resuspended in $1.0 \mathrm{ml}$ of phosphate-buffered saline, and $0.1 \mathrm{ml}$ was solubilized in NCS solubilizer and counted as described. Samples were corrected for quench.

\section{Subjects}

Subjects were healthy adults between 18 and $50 \mathrm{yr}$ who were either nonimmune (nonreactive to $10 \mu \mathrm{g}$ of urushiol by patch test), or immune (reactive to $2 \mu \mathrm{g}$ of urushiol by patch test). Exposure was either accidental (spontaneous) or experimental (induced by applications of 10-20 $\mu \mathrm{g}$ of urushiol on each arm).

\section{RESULTS}

\section{Standard assay}

All the catechols used in this study are very hydrophobic molecules but proved to be highly soluble in cell membranes and were not removed by aqueous washes (described later). RBC membranes or lymphocytes autologous to the responder lymphocytes pro- 
vided a convenient vehicle for adding the alkylcatechols to cultures. Varying numbers of membranes so prepared were added to cultured lymphocytes. Results from a typical microassay for cellular immunity to urushiol is depicted in Fig. 2. Antigen-specific blastogenesis is seen on days 3,4 , and 5 after culture. The range of the optimal dose of antigen is rather narrow. With the standard $\mathrm{RBC}$ antigen preparation ( $0.5 \mathrm{mg}$ of urushiol added to $10^{10} \mathrm{RBC}$ in $5 \mathrm{ml}$ ) the optimal response was obtained with from $8 \times 10^{5}$ to $4 \times 10^{6} \mathrm{RBC}$-uru per culture well. Also compared in Fig. 2 is the response of a subject to HDC, PDC, and urushiol from either poison ivy or poison oak. Like the in vivo response of subjects exposed to either plant $(8,9)$ the in vitro response is high and cross-reactive between urushiols from ivy or oak, and the response to PDC and HDC is about $1 / 10$ that obtained with the urushiols. The subject whose response is depicted here had developed a mild PDC dermatitis 2 wk before testing while working with PDC, so this response is slightly higher than commonly seen. The response is the same whether homologous or autologous RBC-uru is used.

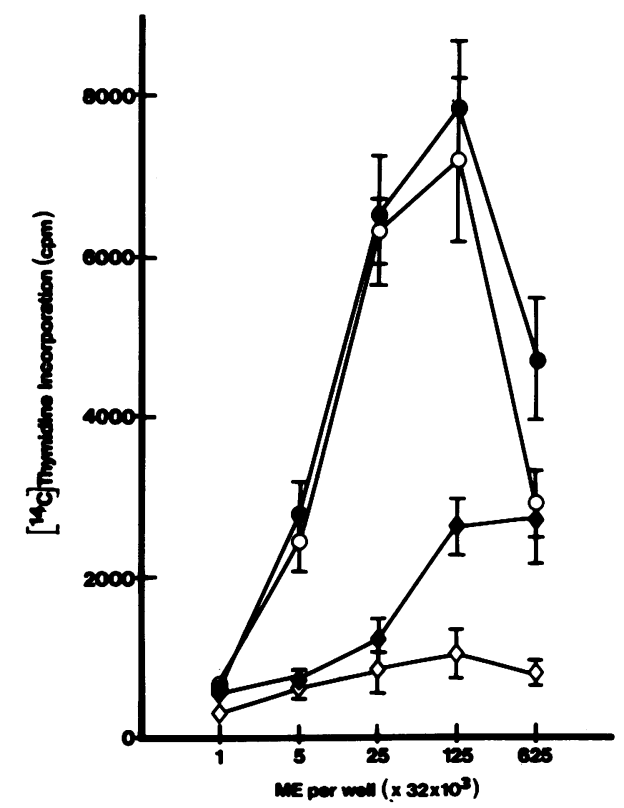

FIGURE 2 Comparison of blastogenesis response to poison oak and ivy oil and PDC and HDC. Cultures of human peripheral blood lymphocytes were stimulated with autologous RBC membranes composed of $0.5 \mathrm{mg}$ alkylcatechol added to $10^{10} \mathrm{RBC}$. Urushiols extracted from poison oak $(\odot)$ or poison ivy $(O)$ were tested as well as PDC $(\diamond)$ and $\operatorname{HDC}(\diamond)$. The donor was initially sensitized to poison ivy, and has been exposed to low levels of poison oak urushiol and PDC numerous times over the past 2 yr. Cultures were pulsed with $\left[{ }^{14} \mathrm{C}\right]$ thymidine days 4 and 5 of culture. Doses of alkylcatechol plotted as RBC ME.
Doses of RBC-uru above $4 \times 10^{6} \mathrm{ME} /$ well produced a diminished blastogenesis response. To determine whether this diminished blastogenic response was a result of a direct toxic effect of the antigen on the responder cells, a series of experiments using lymphocyte mitogens was carried out. These experiments tested the ability of responder lymphocyte populations, from either nonimmune individuals or those responsive in vitro to urushiol, to mount blastogenic reactions to PHA, Con A, and PWM in the presence of RBC-uru. The results of these experiments are shown in Table $I$. The response to the mitogens was lower than normal because the concentration of lymphocytes in the culture wells was selected to be optimal for urushiol responses rather than for mitogen responses.

The results of these experiments demonstrated that the response to the mitogen is not impaired, even with doses of RBC-uru up to $4 \times 10^{7}$ membrane equivalents. In fact, the response to these mitogens, even in the presence of a dose of RBC-uru that was completely inhibitory to the urushiol response, is unaltered or in some cases enhanced. Therefore, although the mechanism is unclear, the inhibition induced by higher doses of urushiol is not a function of direct toxicity to responder $\mathrm{T}$ cells.

\section{Introduction of urushiol to sensitized lymphocytes}

A series of experiments was carried out to investigate the urushiol specific blastogenic response when urushiol was added to cultures on various types of cells or membranes. Responder lymphocytes were shown to react with equal intensity and frequency to urushiol introduced into cultures on either autologous lymphocytes, autologous RBC membranes, or heterologous (sheep) RBC membranes. The results are depicted in Fig. 3. In the first experiment (Fig. 3A), the blastogenesis response to lymphocytes was comparable whether urushiol was added to cultures on autologous RBC or lymphocytes. Both the intensity of response and the dose of urushiol evoking maximal response were comparable with the two types of membrane preparations. Similarly, with a different donor it was demonstrated that both autolgous and heterologous RBC membranes could be used to introduce urushiol into cultures yielding responses of comparable intensity at comparable urushiol doses (Fig. 3B). Similar results were obtained on four additional donors who were reactive to poison oak in vitro. Moreover, 10 individuals who were reactive in vivo but nonreactive in vitro when RBC-uru was used, were also nonreactive in vitro when Ly-uru was used. Therefore, both the intensity and the frequency of reactions were the same regardless of the membrane preparation. 
TABLE I

Influence of Urushiol on the Lymphocyte Blastogenesis Response to Mitogens*

\begin{tabular}{|c|c|c|c|c|c|}
\hline \multirow{2}{*}{$\begin{array}{l}\text { Lymphocyte } \\
\text { donor }\end{array}$} & \multirow[b]{2}{*}{ RBC-uru/well $!$} & \multicolumn{4}{|c|}{$\left[{ }^{[4} \mathrm{C}\right]$ Thymidine uptake into lymphocytes stimulated with } \\
\hline & & No mitogen & PHA & Con A & PWM \\
\hline & & $c p m \pm S E M$ & $c p m \pm S E M$ & $c p m \pm S E M$ & $c p m \pm S E M$ \\
\hline \multirow[t]{4}{*}{1} & None & $513 \pm 6$ & $3,472 \pm 921$ & $7,204 \pm 389$ & $13,191 \pm 369$ \\
\hline & $4 \times 10^{7}$ & $262 \pm 54$ & $8,332 \pm 389$ & $12,589 \pm 222$ & $14,820 \pm 726$ \\
\hline & $1 \times 10^{7}$ & $725 \pm 77$ & $8,013 \pm 581$ & $10,005 \pm 282$ & $15,072 \pm 657$ \\
\hline & $5 \times 10^{6}$ & $592 \pm 73$ & $8,229 \pm 209$ & $10,476 \pm 469$ & $16,059 \pm 666$ \\
\hline \multirow[t]{4}{*}{2} & None & $3,298 \pm 216$ & $9,405 \pm 829$ & $13,579 \pm 343$ & $12,805 \pm 323$ \\
\hline & $4 \times 10^{7}$ & $437 \pm 76$ & $8,585 \pm 577$ & $11,431 \pm 238$ & $8,444 \pm 186$ \\
\hline & $1 \times 10^{7}$ & $1,978 \pm 282$ & $8,331 \pm 573$ & $13,556 \pm 303$ & $13,678 \pm 769$ \\
\hline & $5 \times 10^{6}$ & $1,466 \pm 75$ & $10,648 \pm 796$ & $13,871 \pm 498$ & $14,414 \pm 240$ \\
\hline \multirow[t]{4}{*}{3} & None & $3,805 \pm 88$ & $3,185 \pm 329$ & $5,918 \pm 237$ & $4,276 \pm 263$ \\
\hline & $4 \times 10^{7}$ & $2,151 \pm 128$ & $4,595 \pm 111$ & $6,160 \pm 182$ & $9,325 \pm 294$ \\
\hline & $1 \times 10^{7}$ & $1,900 \pm 258$ & $5,326 \pm 116$ & $8,728 \pm 479$ & $8,812 \pm 668$ \\
\hline & $5 \times 10^{6}$ & $2,868 \pm 152$ & $5,595 \pm 244$ & $10,505 \pm 498$ & $8,426 \pm 97$ \\
\hline
\end{tabular}

* Peripheral blood lymphocytes from subjects not sensitized to poison oak.

$\$$ RBC-uru membranes prepared by adding $0.5 \mathrm{mg}$ of urushiol to $10^{10} \mathrm{RBC}$ in $10 \%$ DMSO-HBSS.

\section{Binding studies}

To determine if the absolute amount of urushiol that produced peak reactivity in cultures with RBC-uru or Ly-uru was the same, a series of binding studies was carried out with $\left[{ }^{3} \mathrm{H}\right] \mathrm{HDC}$, which served as a model for urushiol.

Antigen was prepared by adding urushiol, PDC, or HDC to either RBC or lymphocytes by dissolving the alkylcatechols in DMSO and then adding this solution to suspensions of cells. The amount of alkylcatechol partitioned into cell membranes was more a function of available cell surface area than volume of reaction mixture. Therefore, the number of cells was more important than the reaction volume in determining the amount of alkylcatechol added.

$R B C$. Concentrations of alkylcatechol up to $5 \mathrm{mg} /$ $10^{10} \mathrm{RBC}$ could be used to prepare membrane antigen. Above this concentration the RBC spontaneously lysed and the resultant red-brown tarry precipitate was difficult to use in a quantitative fashion. The amount of alkylcatechol binding was determined with $\left[{ }^{3} \mathrm{H}\right] \mathrm{HDC}$. As shown in Table II, $80-90 \%$ of the total amount of HDC in the 5-ml vol was concentrated in $10^{10} \mathrm{RBC}$ membranes. The HDC was firmly associated with the membranes since it was retained through cell lysis and several water washes and, as shown in Fig. 4, there was an essentially linear uptake with doses of $1-5 \mathrm{mg}$ $\left[{ }^{3} \mathrm{H}\right] \mathrm{HDC} / 10^{10} \mathrm{RBC}$ membranes. This result is consistent with the hydrophobic character of the HDC. Most of the HDC could be removed by three sub- sequent DMSO washes leaving about $2 \%$ of original activity in the membranes (Fig. 4). A more vigorous extraction was performed which involved protein precipitation with $\mathrm{HClO}_{4}$ followed by several homogenizations of the precipitate in ethanolic TCA. This treatment solubilized $\cong 99.9 \%$ of the activity. The remaining label corresponds to a maximum of $1.1 \times 10^{-10} \mu \mathrm{g}(2$ $\times 10^{5}$ molecules) of catechol irreversibly bound per ME (Table II).

Lymphocytes (Ly-uru). The maximal urushiol dose which could be added to $1 \times 10^{7}$ lymphocytes in $5 \mathrm{ml}$ HBSS $-10 \%$ DMSO without causing agglutination was $0.05 \mathrm{mg}$. Amounts higher than $0.05 \mathrm{mg}$ cause Ly-uru to separate as a gummy precipitate and the cells to adhere to the test tube walls. At $0.05 \mathrm{mg}$ urushiol, the lymphocytes were $90 \%$ viable by trypan blue exclusion and ${ }^{51} \mathrm{Cr}$ retention (through three HBSS washes). Experiments using $\left[{ }^{3} \mathrm{H}\right] \mathrm{HDC}$ showed that a substantial amount of alkylcatechol was concentrated in lymphocyte cell membranes. As shown in Table II, $9.2 \%$ of the total $0.05 \mathrm{mg}$ of added alkylcatechol was bound to the lymphocytes, which represents $4.6 \times 10^{-7} \mu \mathrm{g} / \mathrm{cell}$. As was observed with RBC membranes, the alkylcatechol, which remained membrane bound through several aqueous washes, was firmly associated with the lymphocyte membranes. Because the pelleted volume of the lymphocytes is $<0.01 \mathrm{ml}, 10 \%$ of the alkylcatechol in the reaction mixture that remained bound to the lymphocytes after three aqueous washes represented a substantial concentration. If no concentration were occurring one would expect $0.2 \%$ of the alkyl- 

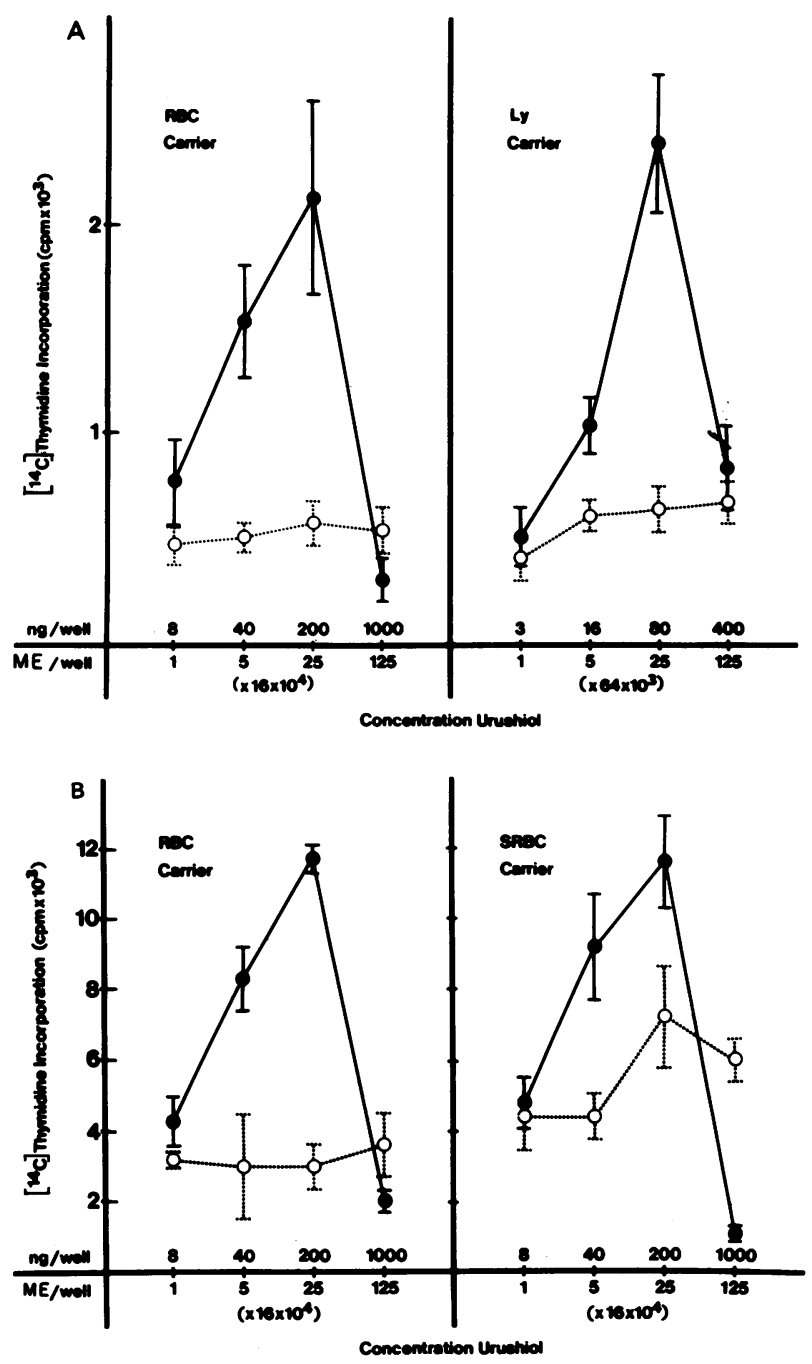

FIGURE 3 Comparison of blastogenesis response of sensitized lymphocytes to urushiol presented either on autologous RBC, heterologous sheep RBC (SRBC), or autologous lymphocytes. Urushiol-treated cells $(--)$, control cells treated with $10 \%$ DMSO (O -..- $\bigcirc)$. (A) Lymphocytes from urushiol-reactive donor 1 were compared as to their reactivity to urushiol on autologous (RBC) or heterologous (sheep RBC) membranes. These antigens were prepared by addition of $0.5 \mathrm{mg}$ urushiol ot $10^{10} \mathrm{RBC}$ in $10 \%$ DMSO-HBSS. (B) Lymphocytes from urushiol-reactive donor 2 were compared as to their reactivity to urushiol on either autologous RBC prepared as in $3 \mathrm{~A}$ above, or on autologous lymphocytes (ly) prepared by adding $0.05 \mathrm{mg}$ urushiol to $10^{7}$ lymphocytes in $10 \%$ DMSO-HBSS. Urushiol is plotted both as the ME/well, or nanograms of urushiol per well, assuming $100 \%$ binding to $\mathrm{RBC}$ and $10 \%$ binding to lymphocytes. Cultures were pulsed with $\left[{ }^{14} \mathrm{C}\right]$ thymidine days 4 and 5 of culture.

catechol to bind to the membranes. After DMSO extraction $\cong 0.8 \%$ alkylcatechol remained associated with the cells, which corresponds to $2 \times 10^{7}$ molecules/ cell. After $\mathrm{HClO}_{4}$ ethanolic TCA homogenization and wash, $<7 \times 10^{-9} \mu \mathrm{g}$ or $1.25 \times 10^{7}$ molecules/cell remained. As with RBC membranes, the number of molecules which could be involved in covalent bonds to the cell membrane protein represents $<0.1 \%$ of the total bound hapten.

\section{Blastogenesis response to urushiol on RBC membranes}

After determining that the great majority of the bound hapten was not covalently associated with cell membranes and that the biologic activity was unrelated to the membrane type used for its introduction, a series of experiments was designed to determine if the optimal urushiol dose could be changed by altering the amount of urushiol associated with the RBC membrane. The results indicate that the biologic reactivity is dependent solely upon the absolute concentration of urushiol in the reaction mixture. Fig. 5 depicts the response of cultured lymphocytes to RBCuru preparations which were prepared with three different concentrations of urushiol, $5 \mathrm{mg}$ urushiol/ $10^{10} \mathrm{RBC}$ (5 RBC-uru), $0.5 \mathrm{mg}$ urushiol $/ 10^{10} \mathrm{RBC}$ (0.5 RBC-uru), and $0.05 \mathrm{mg}$ urushiol/10 ${ }^{10} \mathrm{RBC}$ (0.05 RBCuru). Additionally, preparations of 5 RBC-uru were washed with DMSO, which removes all but $1 \%$ of the urushiol but leaves an active antigen. It was found that maximal reactivity occurred at low numbers of membrane equivalents using 5 RBC-uru, higher numbers when the antigen was $0.5 \mathrm{RBC}$-uru, and highest numbers when the antigen was $0.05 \mathrm{RBC}$-uru. The same number of membrane equivalents for peak reactivity was needed with $0.05 \mathrm{RBC}$-uru as with $5 \mathrm{mg} \mathrm{RBC-uru}$ extracted with DMSO. Thus, the absolute concentration of urushiol per culture, rather than the membrane on which it was introduced, determined reactivity. Additionally, the absolute amount of alkylcatechol per culture was calculated for the experiment shown in Fig. 3, and it was determined that the amount of alkylcatechol producing peak reactivity fell in the same dose range regardless of the membrane preparation in the cultures.

\section{Association of membrane-introduced hapten with lymphocytes}

To determine if alkylcatechols introduced into cultures on RBC membranes become associated with lymphocytes in the culture and whether this association increases with time, $0.5 \mathrm{RBC}-\left[{ }^{3} \mathrm{H}\right]$ hydrourushiol was prepared. This radiolabeled antigen $\left(2 \times 10^{7} \mathrm{ME}\right)$ was mixed with $2 \times 10^{6}$ cultured lymphocytes, reproducing the ratio of the biological assay that produces peak blastogenesis. At varying intervals after culture, mixtures were centrifuged for $10 \mathrm{~min}$ at $200 \mathrm{~g}$, washed 
TABLE III

Increasing Association of RBC Membrane-introduced $\left[{ }^{3} \mathrm{H}\right]$ Hydrourushiol with Cultured Lymphocytes*

\begin{tabular}{ccc}
\hline $\begin{array}{c}\text { Incubation } \\
\text { time }\end{array}$ & $\begin{array}{c}\text { [H]Hydrourushiol } \\
\text { associated with lymphocytes }\end{array}$ & $\begin{array}{c}\text { Percent } \\
\text { association } \$\end{array}$ \\
\hline & mean \pm SEM & \\
$0 \mathrm{~min}$ & $27,906 \pm 3,179$ & 5.96 \\
$30 \mathrm{~min}$ & $31,035 \pm 1,839$ & 6.66 \\
$1 \mathrm{~h}$ & $39,615 \pm 1,733$ & 8.60 \\
$2 \mathrm{~h}$ & $34,093 \pm 1,103$ & 7.35 \\
$4 \mathrm{~h}$ & $46,570 \pm 1,842$ & 10.17 \\
$24 \mathrm{~h}$ & $46,324 \pm 2,373$ & 10.12 \\
$48 \mathrm{~h}$ & $48,674 \pm 2,451$ & 10.65 \\
$120 \mathrm{~h}$ & $66,870 \pm 1,521$ & 14.76 \\
\hline
\end{tabular}

* Control tubes containing RBC- $\left[{ }^{3} \mathrm{H}\right]$ hydrourushiol with no lymphocytes were washed without prior incubation and yielded 1,525 $\pm 797 \mathrm{cpm} /$ tube.

$\ddagger$ Counts per minute per culture. Total counts added to each culture $=444,322 \pm 14,320 \mathrm{cpm}$.

$\S$ Percent association $=\frac{\mathrm{cpm}_{\text {lymphocytes }}-\mathrm{cpm}_{\text {control }}}{\mathrm{cpm}_{\text {total }}-\mathrm{cpm}_{\text {control }}}$.

\section{Characterization of the responder cell population}

The responder cell population was characterized by separating peripheral blood lymphocytes from a reactive donor total population (TP) into T-cellenriched, rosette-rich (RR) and T-cell-depleted, rosettepoor (RP) populations. Each population was tested for its ability to serve as a stimulator or as a responder in the urushiol-specific blastogenesis reaction. A con- centration of $0.05 \mathrm{mg}$ urushiol $/ 10^{7}$ lymphocytes, used to treat stimulator populations, rendered the Ly-uru nonresponsive to mitogen-induced blastogenesis (Table IV) but maintained their viability ( $90 \%$ by trypan blue exclusion) and antigenicity. Table $\mathrm{V}$ depicts the results of such separation experiments. The urushiol responder cell was found in the RR population as can be seen by comparing the response of the RR and RP populations. The RP population produced a small response, probably a result of contamination with reactive $T$ cells. Stimulator capacity resided in the RP population. This is evidenced by comparing the stimulatory ability of the various urushiol carriers: RBC and RR populations were inactive, whereas unseparated lymphocytes and the RP population were stimulatory. Although it appears in Table V that the TP-uru serves as a more efficient stimulator than the RP-uru population, this is probably explained by a shift in the dose of lymphocytes required for maximal stimulation. In fact, the RP-uru population produces a broad doseresponse curve characterized by near-maximal reactivity at stimulator lymphocyte concentrations lower than that required of TP-uru. The peak probably resides between 3.2 and $16 \times 10^{4} \mathrm{ME} /$ well for the RP-uru stimulator population, whereas it is nearer $16 \times 10^{4} \mathrm{ME} /$ well for TP-uru (Fig. 6).

\section{Characterization of the stimulator population}

In an attempt to assess if the macrophage is the cell in the RP population that is responsible for stimulation, the lymphocytes from a responsive donor were de-

TABLE IV

Mitogenic Response of Urushiol-treated Lymphocytes

\begin{tabular}{|c|c|c|c|c|}
\hline \multirow{2}{*}{$\begin{array}{l}\text { Lymphocyte } \\
\text { preparation* }\end{array}$} & \multicolumn{4}{|c|}{$\left[{ }^{14} \mathrm{C}\right]$ Thymidine uptake into lymphocyte preparation stimulated with } \\
\hline & No Mitogen & PHA & Con A & PWM \\
\hline & $c p m \pm S E M$ & $c p m \pm S E M$ & $c p m \pm S E M$ & $c p m \pm S E M$ \\
\hline \multicolumn{5}{|l|}{ Subject 1} \\
\hline Ly-DMSO & $194 \pm 20$ & $19,839 \pm 2,167$ & $15,155 \pm 564$ & $10,677 \pm 370$ \\
\hline Ly-uru, $50 \mu \mathrm{g}$ & $94 \pm 11$ & $116 \pm 15$ & $86 \pm 3$ & $61 \pm 4$ \\
\hline \multicolumn{5}{|l|}{ Subject 2} \\
\hline Ly-DMSO & $146 \pm 7$ & $19,811 \pm 662$ & $9,035 \pm 798$ & $10,063 \pm 575$ \\
\hline Ly-uru, $50 \mu \mathrm{g}$ & $81 \pm 4$ & $86 \pm 13$ & $67 \pm 3$ & $73 \pm 7$ \\
\hline \multicolumn{5}{|l|}{ Subject 3} \\
\hline Ly-DMSO & $167 \pm 12$ & $12,416 \pm 875$ & $12,886 \pm 726$ & $12,483 \pm 444$ \\
\hline Ly-uru, $50 \mu \mathrm{g}$ & $64 \pm 2$ & $72 \pm 6$ & $54 \pm 5$ & $48 \pm 6$ \\
\hline Ly-uru, $10 \mu \mathrm{g}$ & $98 \pm 6$ & $18,172 \pm 666$ & $6,561 \pm 67$ & $3,622 \pm 301$ \\
\hline Ly-uru, $1 \mu \mathrm{g}$ & $119 \pm 21$ & $12,053 \pm 409$ & $12,067 \pm 1,070$ & $11,364 \pm 74$ \\
\hline
\end{tabular}


TABLE V

Comparison of RR, RP, and Total Peripheral Blood

Lymphocytes as Responder and Stimulator Cells

\begin{tabular}{lcc}
\hline \multirow{2}{*}{$\begin{array}{c}\text { Stimulator } \\
\text { cells* }\end{array}$} & \multicolumn{2}{c}{$\begin{array}{c}{\left[{ }^{[4} \text { C]Thymidine uptake of }\right.} \\
\text { lymphocyte subpopulations }\end{array}$} \\
\cline { 2 - 3 } & $\mathrm{RR}$ & $\mathrm{RP}$ \\
\hline none & $c p m \pm S E M$ & $c p m \pm S E M$ \\
RBC-DMSO & $44 \pm 3$ & $86 \pm 7$ \\
RBC-uru & $42 \pm 4$ & $172 \pm 58$ \\
TP-DMSO & $352 \pm 228$ & $1,745 \pm 82$ \\
TP-uru & $242 \pm 54$ & $120 \pm 11$ \\
RR-DMSO & $20,240 \pm 1,458$ & $2,145 \pm 73$ \\
RR-uru & $45 \pm 3$ & $127 \pm 41$ \\
RP-DMSO & $384 \pm 185$ & $1,254 \pm 243$ \\
RP-uru & $2,146 \pm 364$ & $50 \pm 8$ \\
\hline
\end{tabular}

* RBC treated with $10 \%$ DMSO as control or with $0.5 \mathrm{mg}$ of urushiol per $10^{10} \mathrm{RBC}$; all lymphocyte populations were treated with $0.05 \mathrm{mg}$ urushiol per $10^{7}$ lymphocytes or with $10 \%$ DMSO in HBSS as control.

pleted of glass-adherent cells. These lymphocytes were then tested for responsiveness to RBC-uru in the absence and presence of the adherent cells. These adherent cells were determined to be $57 \%$ esterase

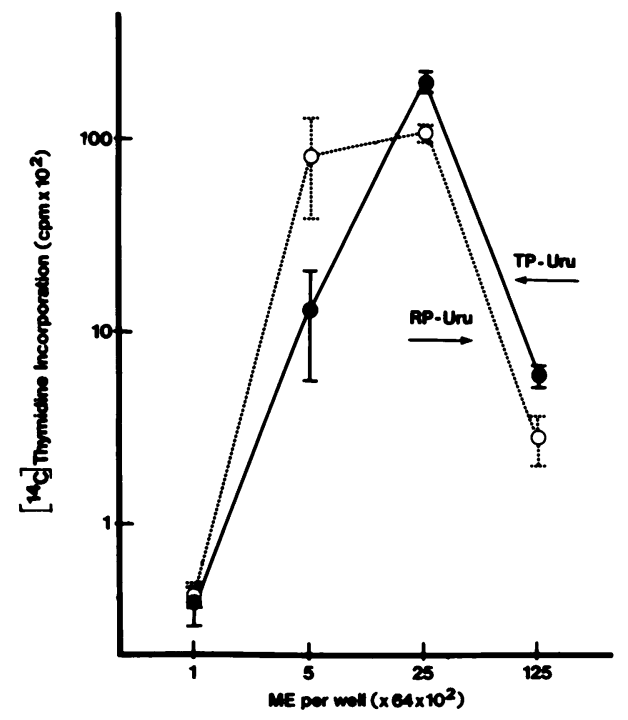

FIgURE 6 Comparison of urushiol-treated RP or TP of lymphocytes as stimulators of RR lymphocytes. Urushiolreactive lymphocytes were separated into RR (T-cell) populations and RP populations. The RR populations were reactive with either urushiol coupled to TP lymphocytes TP-Uru, O), or coupled to RP lymphocytes (RP-Uru, O). Both populations of stimulator lymphocytes were prepared by adding $0.05 \mathrm{mg}$ of urushiol to $10^{7}$ lymphocytes. Included in this experiment were RBC-Uru and RR-Uru populations used as stimulator cells; these results are shown in Table $\mathrm{V}$. positive, and the depleted population was $<3 \%$ esterase positive. Because the dose-response curve of the reaction was so sharp, the cultures were tested at two different RBC-uru concentrations. As shown in Table VI, the total population depleted of macrophages was still capable of responding to RBC-uru. The intensity of the response, however, was reduced to $\cong 40 \%$ of the total nondepleted population. The response was antigen specific as determined by comparison between control and RBC-uru-stimulated cultures and gave an index of 32. Addition of adherent cells increased the intensity of the response to $\cong 70 \%$ of the total nondepleted population.

\section{Epidemiology}

Approximately 55 individuals of differing reactivity to poison oak were tested for in vitro blastogenesis of peripheral blood lymphocytes to RBC-uru. 29 of these who proved to be nonimmune by in vitro testing had been raised in areas where the plants do not grow and they also proved negative by patch testing after blood was drawn for the in vitro tests. 26 individuals who were immune by patch test were tested after spontaneous or experimental exposure to urushiol (Table VII).

All of the individuals who were nonimmne by in vivo testing were also nonreactive in vitro to urushiol. The immune subjects fell into two groups. The first group was reactive in vitro, with reactivity appearing $\cong 1-2$ wk after contact with the oil and subsequent dermatitis. This reactivity lasted about 2 mo and then waned. Out of the 26 immune subjects, 15 were included in this group. The second group of 11 individuals was negative on in vitro testing at various times after the dermatitis. A few individuals showed inhibitory responses (blastogenesis is significantly less than background). The results obtained with this second group of individuals is exemplified by tests on two subjects (A. R. and V. B.).

\section{DISCUSSION}

Urushiol, the hapten that causes contact dermatitis to poison oak, ivy, and sumac, is composed of a family of hydrophobic alkylcatechols. The long aliphatic side chains of these catechols are responsible for the hydrophobic character of the urushiol oil which makes it perhaps the most lipophilic of the haptens that produce contact dermatitis. One consequence of this lipophilicity is a tendency for urushiol to concentrate in cell membranes. This has been verified by the finding that both RBC and lymphocyte membranes concentrated the alkylcatechols up to 100 -fold. Furthermore, the catechols remained so firmly associated with the membranes that they were retained through a series of aqueous washes. However, in contrast to haptens such 


\section{TABLE VI}

Repletion of Blastogenesis Response to RBC-uru in Adherent-cell-depleted Lymphocyte Populations from Urushiol-sensitized Donor

\begin{tabular}{|c|c|c|c|c|c|}
\hline \multirow{4}{*}{ Responder population $t$} & \multicolumn{5}{|c|}{$\left[{ }^{14} \mathrm{C}\right]$ Thymidine uptake into lymphocyte preparations stimulated with } \\
\hline & \multirow{3}{*}{$\begin{array}{c}\text { No antigen } \\
c p m \pm S E M\end{array}$} & \multicolumn{4}{|c|}{ RBC-uru* } \\
\hline & & \multicolumn{2}{|c|}{$8 \times 10^{5 / \text { well }}$} & \multicolumn{2}{|c|}{$4 \times 10^{8} /$ well } \\
\hline & & $c p m \pm S E M$ & $B 1 \S$ & $c p m \pm S E M$ & $B I \S$ \\
\hline Total population" & $3,997 \pm 404$ & $11,111 \pm 960$ & 2.8 & $4,630 \pm 464$ & 1.6 \\
\hline \multicolumn{6}{|c|}{ Nonadherent cells repleted with. . . } \\
\hline No adherent cells & $136 \pm 18$ & $4,341 \pm 998$ & 32.0 & $1,669 \pm 95$ & 12.3 \\
\hline $16 \times 10^{1}$ adherent cells & $321 \pm 29$ & $4,807 \pm 103$ & 15.0 & $1,683 \pm 103$ & 5.3 \\
\hline $8 \times 10^{2}$ adherent cells & $223 \pm 29$ & $5,515 \pm 462$ & 23.0 & $1,554 \pm 192$ & 7.0 \\
\hline $4 \times 10^{3}$ adherent cells & $853 \pm 174$ & $3,625 \pm 619$ & 7.4 & $2,322 \pm 245$ & 2.7 \\
\hline $2 \times 10^{4}$ adherent cells & $2,311 \pm 212$ & $7,503 \pm 697$ & 3.2 & $3,056 \pm 195$ & 1.3 \\
\hline $1 \times 10^{5}$ adherent cells & $3,434 \pm 614$ & $6,457 \pm 260$ & 1.9 & $2,208 \pm 204$ & 0.6 \\
\hline
\end{tabular}

* RBC-uru membranes prepared by adding $0.5 \mathrm{mg}$ of urushiol to $10^{10} \mathrm{RBC}$ in $10 \% \mathrm{DMSO}-\mathrm{HBSS}$.

$\$ 4 \times 10^{5}$ total population of nonadherent cells per culture.

$\S$ Blastogenesis indices calculated by dividing counts per minute of cultures that contain urushiol by counts per minute of cultures that contain no urushiol.

" $6 \%$ esterase positive.

TABLE VII

Blastogenesis Response of Peripheral Blood Lymphocytes from Poison Oak-Sensitive Subjects after Challenge with Urushiol

\begin{tabular}{|c|c|c|c|c|c|c|c|c|c|c|}
\hline \multirow[b]{2}{*}{ Subject } & \multirow{2}{*}{$\begin{array}{l}\text { Type of } \\
\text { exposure* }\end{array}$} & \multicolumn{9}{|c|}{ Blastogenesis indices at various times after exposuret } \\
\hline & & $1 \mathrm{wk}$ & $2 \mathrm{wk}$ & $3 \mathbf{w k}$ & $4 \mathrm{wk}$ & $5 \mathrm{wk}$ & $6 \mathrm{wk}$ & $7 \mathrm{wk}$ & $8 \mathbf{w k}$ & $12 \mathrm{wk}$ \\
\hline F.D. & Spontaneous & & 7.3 & & -2.5 & & & & & \\
\hline E.V. & Experimental & 3.2 & 4.9 & 4.6 & 3.2 & & & 3.9 & 2.1 & 0 \\
\hline S.B. & Spontaneous & & 4.0 & 4.7 & 4.8 & & & 2.1 & & \\
\hline D.K. & Spontaneous & & 2.8 & 3.2 & 3.1 & & & & & \\
\hline J.D. & Spontaneous & & & 26.8 & 10.2 & & & & 4.7 & \\
\hline & Spontaneous & & 0 & 2.5 & & & 3.1 & & & \\
\hline \multirow{2}{*}{ H.J. } & Spontaneous & & 0 & 3.3 & 2.8 & 0 & & 0 & 0 & \\
\hline & Spontaneous & & 2.4 & 2.6 & 0 & 0 & & & & \\
\hline J.M. & Experimental & & 0 & 7.9 & & & 0 & & & 2.9 \\
\hline S.S. & Experimental & & 0 & 5.2 & & & 2.4 & & & 0 \\
\hline M.S. & Experimental & & & 0 & & & 2.8 & & & 0 \\
\hline \multirow[t]{2}{*}{ M.K. } & Spontaneous & & 6.0 & 1.3 & & & & & 24.0 & 11.5 \\
\hline & Experimental & 5.9 & & & 6.6 & & & & & \\
\hline J.G. & Spontaneous & & & & 5.2 & & 0 & & & \\
\hline M.N. & Spontaneous & & & & 2.8 & & & & & \\
\hline M.W. & Spontaneous & & & 2.0 & 0 & 0 & 0 & 0 & & 0 \\
\hline L.S. & Spontaneous & & 24.9 & & & & & & 0 & \\
\hline A.R. & Spontaneous & & 0 & 0 & 0 & & & & 0 & \\
\hline \multirow[t]{3}{*}{ V.B. } & Experimental & -4.8 & 0 & 0 & 0 & 0 & & & & \\
\hline & Experimental & & & & -2.7 & 0 & & & & \\
\hline & Experimental & -2.2 & -6.8 & & & & & & -2.5 & \\
\hline
\end{tabular}

* Spontaneous refers to subjects who accidentally contacted the plant, experimental refers to subjects challenged epicutaneously with urushiol oil in acetone (10-20 $\mu$ g each forearm).

$\ddagger$ Blastogenesis indices calculated by either dividing counts per minute of cultures that contain urushiol by that of those containing no urushiol, or, in the case of the negative indices, by dividing counts per minute of cultures that contain no urushiol by the counts per minute of cultures that contain urushiol. 
as trinitrophenyl in which almost all of the hapten associated with the membranes of lymphocytes is covalently bound $(17,18),>98 \%$ of the catechol associated with RBC and lymphocyte membranes used to introduce antigen into the culture could be removed by DMSO washes.

The relative lack of covalent bonding between urushiol and the cell membranes used for its introduction into the cultures makes the mechanism of antigen presentation unclear. Urushiol-induced contact dermatitis is thought to be a cellular immune reaction directed against the urushiol hapten. It has been suggested that a covalent bond is formed between the catechol ring of the alkylcatechols and a carrier molecule (19). Thus, catechols might dissolve in the lipid membranes and undergo auto-oxidation to form electrophilic o-quinones that would alkylate reactive nucleophilic functionalities on biopolymers. This suggestion is supported by the finding that modification of the catechol ring in a manner that blocks its ability to form the quinone abolishes its reactivity in vivo (19) and in vitro (20). Against this is our finding that the majority of the alkylcatechols in membranes are extractable by organic solvents. This indicates that the catechol moiety may be less reactive to auto-oxidation and covalent bond formation than has been previously proposed (6).

If urushiol could be presented to the immune system as a noncovalently bound hapten that associated with membrane-bound proteins on lymphocytes because of its lipophilic character, one would expect that the reaction induced by urushiol-treated autologous lymphocytes would be markedly greater than that produced by urushiol-treated RBC. Alternatively, if urushiol irreversibly bound to RBC (by the criterion of being retained through organic solvent washes) was seen preferentially by the immune system, then the DMSO-washed RBC-uru should be a more efficient antigen. Neither of these alternatives occurred. In fact, the intensity of reaction was dependent solely upon the absolute amount of alkylcatechol introduced into the culture, and independent of the type of introducing membrane, or nature of the bond between urushiol and that membrane. Therefore, either urushiol is passed from the introducer membrane to another cell in the reactive population which, over the 5-d incubation period forms such a bond, or else urushiol may be utilized by the immune system noncovalently or covalently bound to either type of membrane.

We have shown that hydrourushiol presented to cultures on RBC membranes becomes increasingly associated with cultured lymphocytes over the 5-d incubation time. Also, although the blastogenically active cell is in the T-cell population, some cell in the RP population is required for activity, and this cell could be a macrophage. The requirement for a
RP cell comes from experiments showing that RR ( $T$ cell) populations of responder lymphocytes cannot be stimulated to blastogenesis by RBC-uru, but they respond very well to urushiol added on a RP population. The suggestion that the required cell is a macrophage comes from a separate set of experiments in which reactive lymphocyte populations were depleted of esterase-positive glass-adherent cells and the reactivity of the depleted population was decreased to $\cong 40 \%$ of normal. This activity was repleted by addition of the removed population, which contained $57 \%$ esterase-positive cells. The $40 \%$ residual reactivity remaining after depletion probably represented incomplete removal of macrophages (13), but the ability to replete with a macrophage-enriched population suggests that this is a required cell type. All of these experiments indicate that the catechol ring is not spontaneously reactive. However, under culture conditions a covalent bond may be formed, and this may be an important function of the macrophage. Further studies are in progress to characterize the fate of urushiol in cultures.

In our population studies we found that lymphocytes from $58 \%$ of individuals tested after recent in vivo reaction to poison oak (from $2 \mathrm{wk}$ to $3 \mathrm{mo}$ ) reacted in the antigen-specific in vitro blastogenesis assay. Lymphocytes from nonimmune (naive) and reactive individuals with no history of recent urushiol exposure did not respond in the in vitro assay. Lymphocytes from $42 \%$ of individuals with documented recent in vivo reactivity to urushiol were nonresponsive in vitro. There was internal consistency among individuals reacting either positive or negative in vitro, which confirms the validity of the assay. The number of false negatives in this test could indicate that suppressor cells may be a prominent feature in the human anti-urushiol cellular immune response. This was not noted in studies using hydrophilic moieties such as dinitrochlorobenzene in humans (21) but is consistent with findings in animals $(22-24)$. Alternatively, the ability to present urushiol in an immunogenic fashion in vitro may vary between individuals. This aspect of the urushiol reaction is also under investigation.

\section{ACKNOWLEDGMENTS}

We wish to thank Miss Anne Merrill Knapp and Mr. Eddie Bautista for creative and skilled technical assistance, and Professor R. W. Baldwin for helpful discussions.

This work was supported in part by the National Institutes of Health grants AI 14752 and RO 1 AI 12947; Food and Drug Administration grant 223-77-1201; and by a National Institutes of Health Postdoctoral Fellowship to Dr. Peyton Jacobs.

\section{REFERENCES}

1. Landsteiner, D., and J. Jacobs. 1936. Studies on the sensitization of animals with simple chemical compounds. II. J. Exp. Med. 64: 625-639. 
2. Epstein, W. L. 1974. Poison oak and poison ivy dermatitis as an occupational problem. Cutis. 13: 544-548.

3. Kligman, A. M. 1958. Poison ivy (rhus) dermatitis. Arch. Dermatol. 77: 149-180.

4. California Department of Public Health, Bureau of Occupational Health. 1961. Occupational poison oak dermatitis in California. Berkeley, Calif.

5. Symes, W. F., and C. R. Dawson. 1954. Poison ivy "urushiol." J. Am. Chem. Soc. 76: 2959-2963.

6. Gross, M., H. Baer, and H. M. Fales. 1975. Urushiols of poisonous anarcardiacaea. Phytochemistry (Oxf.). 14: 2263-2266.

7. Corbett, M. D., and S. Billets. 1975. Characterization of poison oak urushiol. J. Pharm. Sci. 64: 1715-1718.

8. Spain, W. C., J. M. Newell, and M. G. Meeker. 1934. The percentage of persons susceptible to poison ivy and poison oak. J. Allergy. 5: 571-574.

9. Johnson, R. A., H. Baer, C. H. Kirkpatrick, C. R. Dawson, and R. G. Khurana. 1972. Comparison of the contact allergenicity of the four pentadecylcatechols derived from poison ivy urushiol in human subjects. J. Allergy Clin. Immunol. 49: 27-35.

10. Dodge, J. T., C. Mitchell, and D. J. Hanahan. 1963. The preparation and chemical characteristics of hemoglobin-free ghosts of human erythrocytes. Arch. Biochem. Biophys. 100: 119-130.

11. Littman, B. 1976. MIF and proliferative response by human lymphocyte subpopulations separated by sheep erythrocyte rosette formation. Cell. Immunol. 24: 241249.

12. Byers, V. S., A. S. Levin, J. O. Johnston, and A. J. Hackett. 1975. Quantitative immunofluroescence studies of the tumor antigen bearing cell in giant cell tumor of bone and osteogenic sarcoma. Cancer Res. 35: 2520-2531.

13. Rosenberg, S. D., and P. E. Lipsky. 1979. Monocyte dependence of pokeweed mitogen-induced differentiation of immunoglobulin secreting cells from human peripheral blood mononuclear cells. J. Immunol. 122: 926-931.

14. Yam, L. T., C. Y. Li, and W. H. Crosby. 1971. Cytochemical identification of monocytes and granulocytes. Am.J. Clin. Pathol. 55: 283-290.
15. Barka, T., and P. J. Andersen. 1962. Histochemical methods for acid phosphatase using hexazonium pararosanilin as coupler. J. Histochem. Cytochem. 10: 741753.

16. Li, C. Y., K. W. Lam, and L. T. Yam. 1973. Esterases in human leukocytes. J. Histochem. Cytochem. 21: 1-12.

17. Forman, J., E. S. Vitetta, D. A. Hart, and J. Klein. 1977. Relationship between trinitrophenyl and $\mathrm{H}-2$ antigens on trinitrophenyl-modified spleen cells. I. H-2 antigens on cells treated with trinitrobenzene sulfonic acid are derivatized. J. Immunol. 118: 797-802.

18. Vitetta, E. S., D. A. Hart, and J. Forman. 1978. Relationship between trinitrophenol and $\mathrm{H}-2$ antigens on trinitrophenyl-modified spleen cells. III. Quantitative aspects of trinitrophenol binding on cells treated with trinitrobenzene sulfonic acid. J. Immunol. 121: 997-1001.

19. Baer, H., R. C. Watkins, and R. T. Bowser. 1966. Delayed contact sensitivity to catechols and resorcinols. The relationship of structure and immunization procedure to sensitizing capacity. Immunochemistry. 3: 479-485.

20. Byers, V. S., N. Castagnoli, Jr., and W. L. Epstein. 1979. In vitro studies of poison oak immunity. II. Effect of urushiol analogues on the human in vitro response.J. Clin. Invest. 64: 1449-1456.

21. Miller, A. E., and W. R. Levis. 1973. Lymphocyte transformation during dinitrochlorobenzene contact sensitization. An in vitro and in vivo evaluation of the primary immune response in man. J. Clin. Invest. 52: 1925-1930.

22. Miller, S. D., M. Sy, and H. N. Claman. 1978. Suppressor T-cell mechanism in contact sensitivity. I. Effluent blockade by syninduced suppressor T cells. J. Immunol. 121: 265-273.

23. Asherson, G. L., M. Zembala, M. A. C. C. Perera, B. Mayhew, and W. R. Thomas. 1977. Production of immunity and unresponsiveness in the mouse by feeding contact sensitizing agents and the role of suppressor cells in the Peyer's patches, mesenteric lymph nodes and other lymphoid tissues. Cell. Immunol. 33: 145-155.

24. Asherson, G. L., P. J. Wood, and B. Mayhew. 1975. Control of the immune response. I. Depression of DNA syntheses by immune lymph node cells. Immunology. 29: 10571065. 